\title{
Update on medical therapy for male LUTS
}

\author{
Sidney B. Radomski, MD, FRCSC \\ Professor of Surgery (Urology), University of Toronto, Toronto Western Hospital, Toronto, ON
}

Cite as: Can Urol Assoc J 2014;8(7-8):S148-50. http://dx.doi.org/10.5489/cuaj.2310

Published online August 11, 2014.

\section{Abstract}

The medical management of lower urinary tract symptoms (LUTS) is aimed at addressing voiding and storage symptoms in patients with benign prostate hyperplasia (BPH) symptoms with or without an overactive bladder (OAB). Current available options for $\mathrm{BPH}$ include alphablockers, 5-alpha reductase inhibitors and phosphodiesterase type 5 inhibitors. For $\mathrm{OAB}$, options include antimuscarinics, with or without an alpha-blocker, the beta-3-adrenergic agonist mirabegron and the synthetic diuretic desmopressin. With the availability of numerous options and combinations available for the treatment of LUTS, individual patient assessment is the key to optimal symptom control and management of adverse effects.

\section{Introduction}

Lower urinary tract symptoms (LUTS) include both storage and voiding symptoms. Storage symptoms, formerly known as irritative symptoms, include frequency, urgency, nocturia, and urgency incontinence. Voiding symptoms, formerly known as obstructive symptoms, include symptoms involving a weak urinary stream, hesitancy, intermittency, straining to void, postmicturition dribbling and feelings of incomplete emptying. ${ }^{1}$ The prevalence and severity of LUTS increases with age ${ }^{2}$ and often has a significant negative impact on quality of life.

\section{Benign prostatic hyperplasia}

The LUTS associated with benign prostatic hyperplasia (BPH) include both storage/irritative symptoms, such as frequency, urgency, nocturia, and voiding/obstructive symptoms, such as hesitancy and straining to void (Table 1). ${ }^{3}$

The treatment of LUTS is guided by the severity of the symptoms, the degree of bother and patient preference (Fig. 1). ${ }^{4}$ The mainstay of medical treatments includes alpha-blockers, 5-alpha-reductase inhibitors (5-ARIs), or a combination of the two. But with the availability of phosphodiesterase type 5 (PDE5) inhibitors and the use of drugs to treat overactive bladder $(\mathrm{OAB})$ there are increased options and combinations to treat patients.

\section{Alpha-blockers}

For patients with moderate to severe LUTS secondary to BPH, alpha-blockers such as alfuzosin, doxazosin, tamsulosin and terazosin are appropriate treatment options. ${ }^{4}$ The selective alpha-blocker silodosin was recently made available in Canada and offers another option. Although there are slight differences in adverse event profiles among these agents, they are considered equally effective, and the choice is driven by the patient's comorbidities, side effect profiles and tolerance. ${ }^{4}$ Alpha-blockers do not alter the natural history of the disease but are very effective for alleviating symptoms.

\section{5-ARls}

The 5-ARIs dutasteride and finasteride are effective treatments for patients with demonstrable prostatic enlargement to prevent progression of LUTS. In addition to improving symptoms, 5-ARIs have been shown to alter the natural history of $\mathrm{BPH}$ by reducing the risk of acute urinary retention (AUR) and the need for surgical intervention through a reduction in prostate volume..$^{5-8}$

Patients with LUTS associated with prostatic enlargement may be offered a combination of an alpha-blocker and a 5-ARI, which has been shown to delay symptomatic disease progression, AUR and prostate surgery compared with either therapy alone. If combination therapy is successful, patients may be given the option of discontinuing the alpha-blocker after 6 to 9 months of therapy, and the alpha-blocker restarted if symptoms recur. ${ }^{4,9}$

\section{PDE5 Inhibitors}

The PDE5 inhibitors, such as sildenafil, vardenafil and tadalafil, have shown improvement in symptoms and quality-of-life in men with LUTS, either with or without ED. ${ }^{10-12} \mathrm{~A}$ recent meta-analysis 


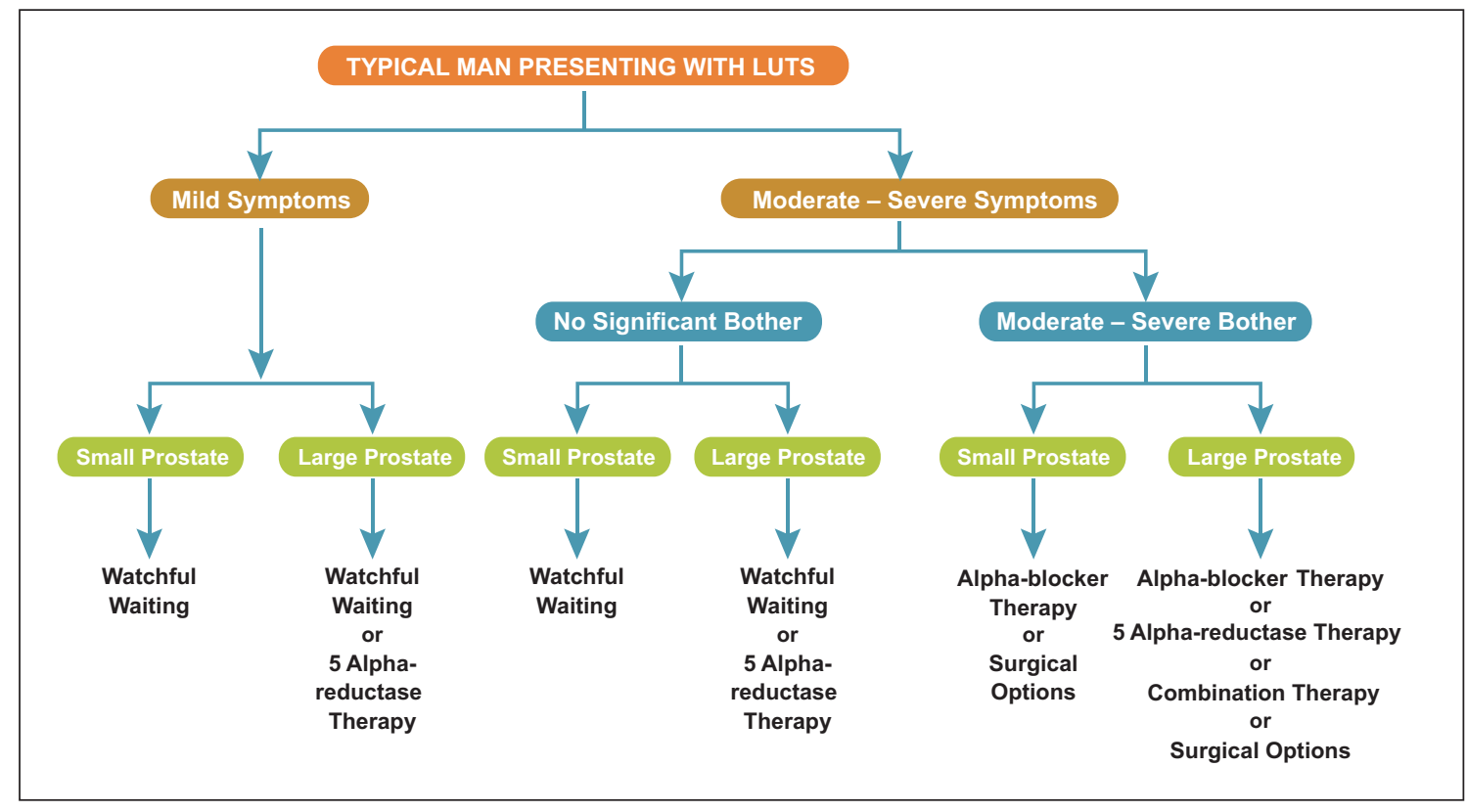

Fig. 1. Therapeutic algorithm for the management of lower urinary tract symptoms. ${ }^{4}$ Copyright $(02010$ Canadian Urological Association. All rights reserved.

demonstrated a 2.8-point decrease in International Prostate Symptom Score (I-PSS) and a 5.5-point increase in the International Index of Erectile Function (IIEF), with no effect on peak urinary flow. ${ }^{13}$ The same meta-analysis showed that a combination of PDE5 inhibitor and alpha-blocker improved IIEF by 3.6 points and lowered I-PSS by 1.8 points, with an increase in peak urinary flow of $1.5 \mathrm{~mL} / \mathrm{s}$ compared with alpha-blocker alone. The CUA guidelines do not currently recommend the use of PDE5 inhibitors for men with symptomatic BPH-related LUTS. ${ }^{4}$ However, when the guidelines are updated they will likely be included in the algorithm.

\section{OAB}

$\mathrm{OAB}$ is a common voiding dysfunction problem characterized by urinary frequency, urgency and at times urgency incontinence. In men, symptoms of OAB may be mistaken for $\mathrm{BPH}$, and many men can suffer from both $\mathrm{OAB}$ and $\mathrm{BPH}$. Over the past number of years there has been has been increased use of anticholinergic medication along with the typical use of alphablockers and 5ARIs to safely treat LUTS in men with BPH. The long standing concerns in the past that anticholinergic drugs were contraindicated due to the risk of retention in these men have been dispelled in numerous studies.

\section{Antimuscarinics}

Antimuscarinics, with or without an alpha-blocker, may be effective for the treatment of the storage symptoms of $O A B$ in some men. In patients with symptoms of $\mathrm{OAB}$, the addition of an antimuscarinic agent such as solifenacin, fesoterodine, tolterodine, or oxybutynin following initial treatment with an alpha1a-selective alpha-blocker has been shown to improve persistent storage symptoms to a greater degree than the alphablocker alone. ${ }^{14-18}$ In men with predominant storage LUTS, antimuscarinic monotherapy is well tolerated and improves symptoms such as bedwetting and urgency urinary incontinence. ${ }^{19-22}$

A concern with the use of antimuscarinics in men with $\mathrm{BPH}$ is the risk of acute urinary retention (AUR). AUR has been reported to occur at a rate of less than $1 \%$ in clinical trials, and in up to $2.5 \%$ in real life practice. ${ }^{23}$ The risk of developing AUR is highest during the first 90 days of treatment. ${ }^{24}$

\section{Mirabegron}

Mirabegron is a beta-3 agonist approved in the United States and Canada for the treatment of OAB. By activating beta-3 receptors in the bladder, mirabegron causes relaxation of the smooth muscle, which results in increased storage capacity of the bladder and a prolonged interval between voids. In a placebo-controlled trial of 200 men with symptoms of LUTS and bladder outlet obstruction, 12 weeks of treatment with mirabegron did not adversely affect voiding parameters on urodynamics, including maximum urinary flow and detrusor pressure at maximum urinary flow, when compared with placebo. ${ }^{25}$

\section{Desmopressin}

Desmopressin acetate is a synthetic form of the anti-diuretic hormone vasopressin, and has been used for the treatment of nocturia and nocturnal enuresis in children and adults. Desmopressin was evaluated in a randomized, double-blind 


\begin{tabular}{lc}
\hline \multicolumn{2}{l}{ Table 1. Lower urinary tract symptoms } \\
\hline $\begin{array}{l}\text { Storage ("irritative") } \\
\text { symptoms }\end{array}$ & Voiding ("obstructive") symptoms $^{\mathbf{3}}$ \\
\hline Frequency & Weak urinary stream \\
Urgency & Hesitancy \\
Nocturia & Intermittency \\
Urgency incontinence & Straining to void \\
& Post-micturition dribbling \\
& Feeling of incomplete emptying \\
\hline
\end{tabular}

trial of 385 men with nocturia, defined as two or more nocturnal voids. Primary end points were changes from baseline in mean number of nocturnal voids and proportions of patients achieving a minimum 33\% reduction from baseline in nocturnal voids. ${ }^{26} \mathrm{~A}$ significant reduction in nocturnal voids $(0.37$ and 0.41 ) was seen by one week - a response that was sustained through the three months of the trial. Desmopressin also significantly increased the odds of having a $33 \%$ reduction in baseline of nocturnal voids, and resulted in significant increases in health-related quality of life and sleep. Hence, desmopressin may be an additional option for men with significant nocturia refractory to other available medication. In clinical practice the use of desmopressin for OAB may have a role in patients with primary nocturnal enuresis who do not have underlying electrolyte disturbance or risk factors for hyponatremia. Older patients in particular are at risk of precipitating fluid retention, hyponatremia, and worsening underlying cardiac failure.

\section{Conclusions}

With the availability of numerous options and combinations for the treatment of LUTS in men, patient selection is the key to optimal symptom control and management of adverse effects. Patients undergoing these treatments require close initial followup to monitor side effects and to assess symptom improvement.

Competing interests: Dr. Radomski is an ongoing paid consultant with Allergan, Astellas, Eli Lilly, Merus Labs, Pfizer, and Watson. He has also received speaker fees, educational grants, and/or travel assistance from Allergan, Astellas, Eli Lilly, and Pfizer within the past 2 years.

\section{References}

1. MCVary KT, Roehrborn CG, Avins AL, et al. Update on AUA guideline on the management of benign prostatic hyperplasia. J Urol 2011;185:1793-803. http://dx.doi.org/10.1016/i.juro.2011.01.074

2. Parsons JK, Bergstrom J, Silberstein J, et al. Prevalence and characteristics of lower urinary tract symptoms in men aged $>$ or $=80$ years. Urology 2008;72:318-21. hittp://dx.doi.org/10.1016/j.urology.2008.03.057

3. McVary KT, Roehrborn CG, Avins AL, American Urological Association Guideline: Management of Benign Prostatic Hyperplasia (BPH). 2010 American Urological Association Education and Research, Inc.

4. Nickel JC, Méndez-Probst CE, Whelan TF, et al. 2010 Update: Guidelines for the management of benign prostatic hyperplasia. Can Urol Assoc J 2010;4:310-6. http://dx.doi.org/10.5489/cuaj.10124

5. Roehrborn CG, Boyle P, Nickel IC, et al. Efficacy and safety of a dual inhibitor of 5-alpha-reductase types 1 and 2 (dutasteride) in men with benign prostatic hyperplasia. Urology 2002;60:434-41. http://dx.doi. org/10.1016/S0090-4295(02)01905-2

6. Roehrborn CG, Siami P, Barkin J, et al. The effects of dutasteride, tamsulosin and combination therapy on lower urinary tract symptoms in men with benign prostatic hyperplasia and prostate enlargement: Two-year results from the CombAT study. J Urol 2008;179:616-21. hitp://dx.doi.org/10.1016/i.juro.2007.09.084
7. McConnell JD, Bruskewitz R, Walsh P, et al and the PLESS Study Group. The effect of finasteride on the risk of acute urinary retention and the need for surgical treatment among men with benign prostatic hyperplasia. $N$ Engl J Med 1998;338:557-63. http://dx.doi.org/10.1056/NEJM199802263380901

8. MCConnell JD, Roehrborn CG, Oliver OM, et al for the MTOPS Research Group. The long term effect of doxazosin, finasteride and combination therapy on the clinical progression of benign prostatic hyperplasia. N Engl J Med 2003;349:2385-96. http://dx.doi.org/10.1056/NEJMoa030656

9. Barkin J, Guimarães $M$, Jacobi $G$, et al. Alpha-blocker therapy can be withdrawn in the majority of men following initial combination therapy with the dual 5alpha-reductase inhibitor dutasteride. Eur Urol 2003;44:461-6. http://dx.doi.org/10.1016/S0302-2838(03)00367-1

10. Brock $G$, Broderick $G$, Roehrborn $C G$, et al. Tadalafil once daily in the treatment of lower urinary tract symptoms (LUTS) suggestive of benign prostatic hyperplasia (BPH) in men without erectile dysfunction. BJU Int 2013;112:990-7.

11. MCVary KT, Kaufman J, Young JM, et al. Sildenafil citrate improves erectile function: A randomised doubleblind trial with open-label extension. Int I Clin Pract 2007;61:1843-9. http://dx.doi.org/10.1111/j.17421241.2007.01585.x

12. Tuncel $A$, Nalcacioglu $V$, Ener $K$, et al. Sildenafil citrate and tamsulosin combination is not superior to monotherapy in treating lower urinary tract symptoms and erectile dysfunction. World J Urol 2010;28:17-22. http://dx.doi. org/10.1007/s00345-009-0484-z

13. Gacci $M$, Corona $G$, Salvi $M$, et al. A systematic review and meta-analysis on the use of phosphodiesterase 5 inhibitors alone or in combination with $\alpha$-blockers for lower urinary tract symptoms due to benign prostatic hyperplasia. Eur Urol 2012;61:994-1003. http://dx.doi.org/10.1016/i.eururo.2012.02.033

14. MacDiarmid SA, Peters KM, Chen A, et al. Efficacy and safety of extended-release oxybutynin in combination with tamsulosin for treatment of lower urinary tract symptoms in men: Randomized, double-blind, placebo-controlled study. Mayo Clin Proc 2008;83:1002-10. http://dx.doi.org/10.4065/83.9.1002

15. Chapple C, Herschorn $S$, Abrams $P$, et al. Tolterodine treatment improves storage symptoms suggestive of overactive bladder in men treated with alpha-blockers. Eur Urol 2009;56:534-41. http://dx.doi.org/10.1016/i. eururo.2008.11.026

16. Kaplan SA, McCammon K, Fincher R, et al. Safety and tolerability of solifenacin add-on therapy to alpha-blocker treated men with residual urgency and frequency. J Urol 2009;182:2825-30. http://dx.doi.org/10.1016/i. juro.2009.08.023

17. Yamaguchi 0, Kakizaki H, Homma Y, et al; ASSIST Study Group. Solifenacin as add-on therapy for overactive bladder symptoms in men treated for lower urinary tract symptoms-ASSIST, randomized controlled study. Urology 2011;78:126-33. http://dx.doi.org/10.1016/j.urology.2011.02.055

18. Kaplan SA, Roehrborn CG, Gong J, et al. Add-on fesoterodine for residual storage symptoms suggestive of overactive bladder in men receiving $\alpha$-blocker treatment for lower urinary tract symptoms. BJU Int 2012;109: 183140. http://dx.doi.org/10.1111/i.1464-410X.2011.10624.x

19. Roehrborn $C G$, Abrams $P$, Rovner $E S$, et al. Efficacy and tolerability of tolterodine extended-release in men with overactive bladder and urgency urinary incontinence. BJU Int 2006;97:1003-6. http://dx.doi.org/10.1111/ j.1464-410X.2006.06068.x

20. Kaplan SA, Roehrborn CG, Dmochowski R, et al. Tolterodine extended release improves overactive bladder symptoms in men with overactive bladder and nocturia. Urology 2006;68:328-32. http://dx.doi.org/10.1016/i. urology.2006.03.006

21. Dmochowski R, Abrams $P$, Marschall-Kehrel $D$, et al. Efficacy and tolerability of tolterodine extended release in male and female patients with overactive bladder. Eur Urol 2007;51:1054-64. http://dx.doi.org/10.1016/i. eururo.2006.10.005

22. Herschorn $\mathrm{S}$, Jones IS, Oelke $M$, et al. Efficacy and tolerability of fesoterodine in men with overactive bladder: A pooled analysis of 2 phase III studies. Urology 2010;75:1149-55. http://dx.doi.org/10.1016/i. urology.2009.09.007

23. Huang $\mathrm{E} Y-\mathrm{H}$, Lin $\mathrm{C}-\mathrm{C}$, Chung $\mathrm{H}-\mathrm{J}$, et al. Urinary retention following antimuscarinics in patients with $\mathrm{BPH}$ in real life practice - A nation-wide database study. American Urological Association Annual Meeting; San Diego, CA; May 4-8, 2013. Abstr 1386.

24. Lin ATL, Huang E Y-H, Lin C-C, et al. The association between the duration of antimuscarinics use and urinary retention in patients with BPH-A nation-wide database study. American Urological Association Annual Meeting; San Diego, CA; May 4-8, 2013. Abstr 1388.

25. Nitti VW, Rosenberg S, Mitcheson DH, et al. Urodynamics and safety of the $\beta_{3}$-adrenoceptor agonist mirabegron in males with lower urinary tract symptoms and bladder outlet obstruction. J Urol 2013;190:1320-7. http:// dx.doi.org/10.1016/i.juro.2013.05.062

26. Weiss JP, Herschorn S, Albei CD, et al. Efficacy and safety of low dose desmopressin orally disintegrating tablet in men with nocturia: Results of a multicenter, randomized, double-blind, placebo controlled, parallel group study. J Urol 2013;190:965-72. http://dx.doi.org/10.1016/i.juro.2012.12.112

Correspondence: Dr. Sidney B. Radomski, Toronto Western Hospital, Main Pavilion, 8th Floor Rm. 304, 399 Bathurst St., Toronto, ON M5T 2S8; sidney.radomski@uhn.ca 